\title{
Consumer confidence in the safety of milk and infant milk formula in China
}

\author{
Saiwei Li, ${ }^{1,2}$ Siet J. Sijtsema, ${ }^{3}$ Marcel Kornelis, ${ }^{3}$ Yumei Liu, ${ }^{1,2 *}$ and Shengli Li ${ }^{4 *}$ \\ ${ }^{1}$ Beijing Food Safety Policy \& Strategy Research Base, China Agricultural University, No.17 Tsinghua East Road, Haidian District, 100083 Beijing, \\ P. R. China \\ ${ }^{2}$ College of Economics and Management, China Agricultural University, 108 Mailbox, No.17 Tsinghua East Road, Haidian District, 100083 Beijing, \\ P. R. China \\ ${ }^{3}$ Wageningen University \& Research, Wageningen Economic Research, PO Box 35, Wageningen 6700 AA, the Netherlands \\ ${ }^{4}$ College of Animal Science and Technology, China Agricultural University, No. 2 Yuanmingyuan West Road, Haidian District, 100094 Beijing, \\ P. R. China
}

\section{ABSTRACT}

A series of food safety incidents related to domestically produced dairy in China harmed consumer confidence and caused a dramatic decrease in dairy consumption from 2008 to 2010. Compared with previous studies that mainly assessed consumer confidence in food or dairy in general, this study focused on 2 specific dairy products, milk and infant milk formula (IMF). Based on data from 934 Chinese consumers, confidence in the safety of milk and IMF was measured by using a multi-item scale with 2 dimensions - optimism and pessimism. We found that Chinese consumers were optimistic about the safety of milk and IMF but, at the same time, were concerned about the risks related to milk and IMF. Chinese consumers have less confidence in IMF than in milk. Structural equation modeling indicated that consumer trust in manufacturers and third parties in the dairy supply chain and confidence in other foods, such as meat and fish, can foster consumer confidence in the safety of milk and IMF, while the extent of recall of the melamine infant formula incident in 2008 and trait worry exert negative effects. In addition, consumers with more children or less family income are likely to be more confident in domestically produced IMF. These insights into consumer confidence and its determinants can assist dairy supply chains and regulatory institutions in formulating effective risk communication strategies to strengthen consumer confidence.

Key words: consumer confidence, food safety, trust, infant milk formula

Received March 17, 2019.

Accepted June 25, 2019.

*Corresponding authors: ymliu8028@cau.edu.cn and lisheng0677@ 163.com

\section{INTRODUCTION}

A series of food safety incidents in domestically produced dairy products harmed Chinese consumers' confidence, and the most serious one was the melaminecontaminated infant formula incident on September 11, 2008. In that incident, infant milk formula (IMF) produced by the Sanlu Dairy Company was confirmed to be tainted with melamine, a chemical that can cause kidney stones in infants and increase the risk of renal failure and even death. Approximately 300,000 children became ill, and 6 infants died from consuming the melamine-contaminated IMF. As a result, many Chinese consumers turned to imported IMF for quality assurance, despite higher prices (Xiu and Klein, 2010).

To improve the safety of domestic dairy products and restore consumer confidence, the Chinese government carried out the following actions. First, a new Food Safety Law was introduced in 2009, which was instrumental in developing unified national standards of food safety, abolishing inspection-free food items, and immediate recalling of any food that does not meet food safety standards (Xiu and Klein, 2010). Second, more stringent inspection of the milk collection stations was developed by provincial and regional agriculture departments (Xiu and Klein, 2010). Third, the maximum tolerance level for melamine in IMF products was introduced, following the Codex Alimentarius Commission (People's Daily, 2012). Although empirical evidence indicates that the safety of China's IMF products increased (Dairy Association of China and Ministry of Agriculture and Rural Affairs of China, 2018), these positive developments do not seem to have attracted Chinese consumers back to domestic dairy. For example, China imported 324,500 t of IMF in 2018, nearly 8 times the amount imported in 2008 (http:/ /news.china.com/domesticgd/10000159/20160609/ 22839188.html, accessed April 26, 2018; http://www .sohu.com/a/309566226_120004044, accessed June 21, 2019), resulting in substantial profit losses for domestic 
dairy firms, even seriously threatening their survival. Thus, regaining consumer confidence remains the key to reviving China's domestic dairy industry. To this end, a better understanding of consumer confidence and its determinants is needed to formulate food risk communication strategies to restore and improve consumer confidence in products from the Chinese dairy industry.

Previous studies that considered Chinese consumer confidence in the safety of dairy products used primarily single-item measures (Lu, 2010; Qiao et al., 2010). However, studies about confidence in food in general, such as de Jonge et al. (2007), show that confidence is 2-dimensional; namely, optimism and pessimism, and should therefore be measured with multi-item scales. In this study, we followed this approach.

de Jonge (2008) identified several potential determinants related to consumer confidence in food safety. First, consumer trust in the actors in the food supply chain is considered an important driver of consumer confidence (Berg et al., 2005; de Jonge et al., 2007). As the food production system becomes more complex, consumers tend to place more weight on trust in the actors involved in the food system to compensate for their lack of knowledge of food safety (Lassoued et al., 2015). Second, consumers' recall of food safety incidents over the past 6 mo reduces their confidence in food safety. Third, consumer confidence in specific product groups, such as meat and fish, contributes to consumer confidence in the safety of food in general. Fourth, consumer concerns about food-related hazards are responsible for low consumer confidence in food safety. Consumer confidence in food safety is also related to individual differences; for example, consumers who are more prone to worry magnify the gravity of food safety incidents and tend to be more negative about food safety (see also Xu et al., 2011; Gong et al., 2012).

In this study, we considered both dimensions of confidence and investigated the potential determinants based on the above framework of de Jonge (2008), which allows a more comprehensive understanding of the current level of Chinese consumer confidence in dairy products nearly $10 \mathrm{yr}$ after the melamine incident. In doing so, we investigated consumer confidence in 2 types of dairy product, milk and IMF, which are both domestically produced and provide a basis for analyzing the mechanisms by which consumer confidence varied across different products of the same product group.

In addition, we also discuss the following 3 factors that may also affect Chinese consumer confidence in milk and IMF. First, we examined the effect of trust in third parties on consumer confidence in milk and IMF, which has not yet received much attention. Third parties have begun to play a more important role in guar- anteeing the safety of dairy products in China (Wang et al., 2008). Understanding the influence of trust in third parties is helpful to improve the diversity of risk communication strategies. Second, we studied the extent to which the melamine incident influences the current level of consumer confidence; we expected that the melamine incident still negatively affects consumer confidence in dairy products, especially IMF. Finally, we investigated whether consumer confidence in other food groups is related to consumer confidence in dairy products. It is assumed that consumers who perceive other foods such as meat to be unsafe may also be skeptical about and lack confidence in the safety of milk and IMF.

\section{MATERIALS AND METHODS}

\section{Data Collection}

The empirical analysis was based on data from urban and rural consumers in 5 cities: Beijing, Shanghai, Shijiazhuang, Xi'an, and Harbin, as well as their counties and villages in China. Beijing and Shanghai are first-tier cities located in northern and eastern China, respectively. Shijiazhuang, Xi'an, and Harbin are second-tier cites in the northern, western, and northeast regions of China, respectively. In terms of economic development and wealth, the annual disposable incomes per capita in Shanghai and Beijing were $\$ 9,373$ and $\$ 9,094$, respectively (National Bureau of Statistics of China, 2018), ranking first and second in China in 2017; the annual disposable incomes per capita in Xi'an, Harbin, and Shijiazhuang were $\$ 5,180, \$ 4,466$, and $\$ 3,917$, respectively ( $\$ 1=6.2933$ yuan; accessed April 21, 2018) The first 2 incomes per capita are above the national average level of $\$ 4,127$, whereas the last is below the national average (Harbin Bureau of Statistics, 2018; National Bureau of Statistics of China, 2018; Shijiazhuang Bureau of Statistics, 2018; Xi'an Bureau of Statistics, 2018).

Data were collected through a cross-sectional survey based on stratified multistage sampling. Three steps were involved in data collection. First, a sampling frame was created at the city district level. Two city districts from each city were randomly selected. Then, 50 consumers were randomly selected in each city district. This approach identified 10 sample city districts and 500 sampled city consumers. Second, a stratified random sample of counties was chosen from each of the 5 cities for a total sample of 5 counties, and 50 consumers were randomly selected in each county. This approach identified 5 sample counties and 250 sampled county consumers. Finally, the sampling process consisted of selecting 2 villages from each county, and then randomly selecting 25 consumers in each village. This 
Table 1. The distribution of samples (number and \%) in urban and rural areas of the 5 cities

\begin{tabular}{|c|c|c|c|c|c|c|c|c|}
\hline City & \multicolumn{2}{|c|}{ City district } & \multicolumn{2}{|c|}{ County } & \multicolumn{2}{|c|}{ Village } & \multicolumn{2}{|c|}{ City } \\
\hline Beijing & 96 & 50.53 & 48 & 25.26 & 46 & 24.21 & 190 & 20.34 \\
\hline Xian & 96 & 50.53 & 48 & 25.26 & 46 & 24.21 & 190 & 20.34 \\
\hline Harbin & 100 & 50.76 & 53 & 26.90 & 44 & 22.34 & 197 & 21.09 \\
\hline Shanghai & 91 & 51.12 & 47 & 26.40 & 40 & 22.47 & 178 & 19.06 \\
\hline
\end{tabular}

${ }^{1}$ Percent is the proportion of city district (or county, village) samples in the city.

${ }^{2}$ Percent is the proportion of samples from each city in the total samples.

approach identified 10 sample villages and 250 sampled village consumers. The survey was conducted from July to August 2017. A total of 1,000 consumer responses, including 500 city consumers, 250 county consumers, and 250 village consumers, were recorded. Excluding nonresponses, data from 934 sample consumers were included in the final analysis.

Before the formal investigation, we carried out a pilot study among 10 participants in Beijing, which yielded improvements in the questionnaire design. The distribution of samples in urban and rural areas of the 5 cities is shown in Table 1.

\section{Characteristics of the Sample}

The sociodemographic characteristics of the respondents are summarized in Table 2. The majority (68.74\%) of the respondents were female, and $48.18 \%$ of the respondents were between 26 and $55 \mathrm{yr}$ of age. The level of education was relatively high; the highest education level of $33.83 \%$ respondents was college, and $53.74 \%$ respondents had junior high school or high school as their highest education level. The main reason for the relatively high education levels was that we conducted surveys in 5 relatively developed cities in China, which have more consumers with higher education levels. Approximately $74.20 \%$ of respondents' family income was below $\$ 1,589 / \mathrm{mo}$. Nearly $70.00 \%$ of the respondents were highly positive about their own health; and $4.50 \%$ of the respondents indicated lactose intolerance. This widely distributed survey area ensured that the study sample was a good representation of Chinese consumers.

\section{Questionnaire}

The questionnaire assessed the following topics: consumer confidence in the safety of milk and IMF, consumer trust in different actors in the dairy supply chain, consumer confidence in other foods, consumer concerns about dairy product-related issues, extent of recall of the melamine incident, consumers' recall of food safety incidents in the past $6 \mathrm{mo}$, trait worry, and sociodemographics. All items were scored on 5-point Likert scales.

Consumer Confidence in the Safety of Chinese Milk and IMF. Consumer confidence in the safety of Chinese milk and IMF was measured using a 7-item scale developed and validated in the Netherlands and

Table 2. The sociodemographic characteristics of respondents

\begin{tabular}{|c|c|c|}
\hline Item & $\begin{array}{l}\text { No. of } \\
\text { respondents }\end{array}$ & $\%^{1}$ \\
\hline \multicolumn{3}{|l|}{ Sex } \\
\hline Male & 292 & 31.26 \\
\hline Female & 642 & 68.74 \\
\hline \multicolumn{3}{|l|}{ Age (yr) } \\
\hline $18-25$ & 225 & 24.09 \\
\hline $26-35$ & 273 & 29.23 \\
\hline $36-45$ & 177 & 18.95 \\
\hline $46-55$ & 142 & 15.20 \\
\hline$\geq 56$ & 117 & 12.53 \\
\hline \multicolumn{3}{|l|}{ Lactose intolerance } \\
\hline Yes & 42 & 4.50 \\
\hline No & 892 & 95.50 \\
\hline \multicolumn{3}{|c|}{ Number of children in family } \\
\hline 0 & 530 & 56.75 \\
\hline 1 & 313 & 33.51 \\
\hline$\geq 2$ & 91 & 9.74 \\
\hline \multicolumn{3}{|l|}{ Education } \\
\hline Elementary school & 62 & 6.64 \\
\hline Junior high school & 244 & 26.12 \\
\hline High school & 258 & 27.62 \\
\hline College/university & 316 & 33.83 \\
\hline Graduate studies & 54 & 5.78 \\
\hline \multicolumn{3}{|l|}{ Health } \\
\hline Very good & 252 & 26.98 \\
\hline Good & 390 & 41.76 \\
\hline Normal & 262 & 28.05 \\
\hline Poor & 26 & 2.78 \\
\hline Very poor & 4 & 0.43 \\
\hline \multicolumn{3}{|c|}{ Family income (US $\$ / \mathrm{mo})^{2}$} \\
\hline $0-794$ & 363 & 38.87 \\
\hline $794-1,589$ & 330 & 35.33 \\
\hline$>1,589$ & 241 & 25.80 \\
\hline
\end{tabular}

${ }^{1}$ Proportion of samples with different characteristics in the respondents.

${ }^{2}$ According to exchange rate: $\$ 1=6.2933$ yuan, $\$ 794=5,000$ yuan, $\$ 1,589=10,000$ yuan . 
Canada by de Jonge (2008). This scale consists of the 2 distinct dimensions of confidence: optimism and pessimism. With respect to milk, for example, optimism was measured by 4 items, "I am optimistic about the safety of milk," "I am satisfied with the safety of milk," "I am confident that milk is safe," and "In general, milk is safe." Pessimism was measured using the items, "I worry about the safety of milk," "I feel uncomfortable regarding the safety of milk," and "As a result of the occurrence of dairy safety incidents, I am suspicious about milk." All items were scored from $1=$ strongly disagree to $5=$ strongly agree.

Consumer Trust in Different Actors of the Dairy Supply Chain Regarding the Safety of Dairy. Consumer trust in the main actors of the dairy supply chain, including government, farmers, retailers, dairy manufacturers, and third parties, was measured. To ensure the understanding of respondents, the interviewers introduced the concept of a "third party" as "an independent institution which is responsible for detecting the quality and safety of dairy products." Consequently, interviewers mentioned the China Dairy Association Quality Monitoring Center to respondents as an example. For each actor, respondents were asked to score 6 items adopted from de Jonge (2008) (ranging from $1=$ strongly disagree to $5=$ strongly agree). Using farmers as an example, the statements were as follows: (a) farmers have the competence to control the safety of dairy; (b) farmers have sufficient knowledge to guarantee the safety of dairy; (c) farmers are honest about the safety of dairy; (d) farmers are sufficiently open about the safety of dairy; (e) farmers take good care of the safety of dairy; and (f) farmers give special attention to the safety of dairy.

Confidence in Other Food Products. Consumer confidence in other food products, including beef, pork, fresh vegetables, poultry, and seafood, was measured based on de Jonge (2008). Respondents were asked the question "How much confidence do you have in the safety of these products?" and scored the question from $1=$ no confidence at all to $5=$ complete confidence.

Consumer Concerns About Dairy-Related Issues. Respondents were asked about their concerns about 21 dairy product-related hazards (see Appendix Table A1). Many of the issues in the study of de Jonge (2008) were adjusted to dairy production and dairyrelated health hazards. In addition, we added some China-specific issues that are related to dairy-related safety incidents or relevant to dairy consumption. Each dairy-related issue was evaluated from $1=$ not at all concerned to $5=$ very much concerned.

Consumers' Recall of Food Safety Incidents and Extent of Recall of the 2008 Melamine Incident. To measure consumers' memory of food safety incidents, respondents were asked whether they remembered a particular incident over the past 6 mo where the safety of food was compromised or threatened (yes/ no) based on de Jonge (2008). The extent of recall of the 2008 melamine incident was measured with the statement "it still affects my consumption behavior of dairy today" and scored from $1=$ strongly disagree to $5=$ strongly agree.

Trait Worry. Respondents were asked to score 3 items from the Penn State Worry Questionnaire (Gebhardt and Brosschot, 2002) (ranging from $1=$ strongly disagree to $5=$ strongly agree): "Many situations make me worry," "I notice that I have been worrying about things," and "I know I shouldn't worry about things, but I just cannot help it."

Sociodemographics. The sociodemographics in this survey included sex, age, education, family income, and the number of children in the household. In addition, respondents were asked to evaluate their own health by scoring their health from $1=$ very good to $5=$ very poor. Respondents were also asked whether they had lactose intolerance (yes/no).

\section{Data Analysis}

The survey data were analyzed using SPSS 22 (IBM Corp., Armonk, NY). Exploratory factor analysis using principal components was performed to explore the underlying dimensional structure of 2 sets of measures: consumer confidence in the safety of other food products and consumer concerns about dairy-related issues. Regarding consumer confidence in the safety of other foods, all items were loaded on one factor that explained $59.77 \%$ of the total variance. Regarding consumer concern about dairy-related issues, 3 factors were identified and explained $63.61 \%$ of the total variance. Eight items were excluded using backward selection when factor loadings were lower than 0.60 (following Field, 2009) and when the items strongly loaded on 2 or more factors (following Costello and Osborne, 2005). The 3 factors were labeled "production method-related issues" (5 items), "safety assurance" (5 items), and "health-related issues" (3 items; see Appendix Table A1). The Cronbach $\alpha$ coefficients of all constructs were $>0.70$, providing evidence of satisfactory construct reliability.

\section{Structural Equation Modeling}

Two structural equation models investigated the determinants of consumer confidence in the safety of Chinese milk and IMF. We used SPSS Amos Version 24 (SPSS Inc.) and followed the steps outlined in Anderson and Gerbing (1988). A structural equation 
model consists of 2 main components: the measurement model (outer model), which describes the relationship between constructs and their items, and the structural model (inner model), which defines the dependencies among the constructs. Before the variables entered the structural model, 2 confirmatory factor analyses were conducted for milk and IMF among the 14 latent variables to investigate the reliability and the validity of constructs in the measurement model. Construct validity was analyzed by studying the factor loadings (Anderson and Gerbing, 1988), which was acceptable when factor loadings of all items in every latent variable were $>0.40$ (Blunch, 2008). Meanwhile, the scores of factor loadings were statistically significant, as indicated by their corresponding $P$-value $(<0.01)$, providing support for convergent validity of all constructs (Anderson and Gerbing, 1988; Bollen, 1989). Construct reliability was assessed by 2 internal consistency indicators: composite reliability $(\mathbf{C R})$ and average variance extracted (AVE) measures. A CR $>0.70$ indicated that the measurement scales had high internal consistency (Nunnally, 1978). An AVE $>0.50$ indicated that the variance captured by a construct was larger than the variance due to measurement errors (Fornell and Larcker, 1981). Consequently, the results of the measurement model were used to test the postulated paths for statistical significance between the constructs. Maximum likelihood estimation was applied to assess the fit of the model to the data. Model fit was assessed via the normalized chi-squared $\left(\chi^{2} / \mathrm{df}\right)$, the root mean square error of ap- proximation (RMSEA), and the comparative fit index $(\mathbf{C F I})$. Normalized $\chi^{2}$ values within the recommended level of 2.00 to 3.00 , demonstrated an adequate model fit (Carmines and McIver, 1981). Values $<0.08$ for RMSEA and values $>0.90$ for CFI indicated an acceptable fit of the model (Bollen, 1989; Browne and Cudeck, 1993).

\section{RESULTS}

\section{Consumer Confidence in the Safety of Chinese Milk and IMF}

The descriptive statistics of consumer confidence in milk and IMF and other constructs are presented in Table 3. The mean scores (SD) of optimism and pessimism for milk were $3.53(0.63)$ and $3.15(0.69)$, respectively, and for IMF were $3.31(0.66)$ and 3.35 (0.69), respectively. All the scores were above the midpoint of the 5-point scale, showing that consumers were not only optimistic about the safety of milk and IMF but also pessimistic about the risks related to milk and IMF. In comparing the mean scores of the 2 dimensions of confidence, the mean score of optimism for Chinese milk was significantly higher than that of optimism for $\operatorname{IMF}(t=11.86, P<0.0001)$, whereas the mean score of pessimism for milk was significantly lower than that of pessimism for IMF $(t=9.22, P<0.0001)$. This showed that the respondents indicated a higher confidence in milk than in IMF.

Table 3. Mean scores (SD) of multi-item measuring constructs

\begin{tabular}{lccc}
\hline Construct & Mean $^{1}$ & SD & $P$-value \\
\hline Consumer confidence & & & \\
Optimism_milk & 3.53 & 0.63 & $<0.01^{2}$ \\
Optimism_infant milk formula & 3.31 & 0.66 & $<0.01^{2}$ \\
Pessimism_milk & 3.15 & 0.69 & \\
Pessimism_infant milk formula & 3.35 & 0.69 & \\
Consumer trust in actors of dairy supply chain & & & \\
Trust in manufacturers & 3.64 & 0.58 & $<0.01^{3}$ \\
Trust in retailers & 3.31 & 0.71 & \\
Trust in farmers & 3.36 & 0.72 & \\
Trust in government & 3.70 & 0.70 & \\
Trust in third parties & 3.58 & 0.66 & \\
Consumer confidence in other foods & 3.50 & 0.65 & \\
Concerns about dairy-related issues & & & \\
Production method & 4.03 & 0.73 & $<01^{3}$ \\
Safety assurance & 4.09 & 0.61 & \\
Health related & 3.46 & 0.82 & \\
Trait worry & 3.31 & 0.72 & \\
\hline
\end{tabular}

${ }^{1}$ The mean value is the mean of the scale divided by the number of items.

${ }^{2} \mathrm{~A}$ paired $t$-test was used to test for differences in optimism and pessimism between milk and infant milk formula.

${ }^{3}$ A one-way ANOVA was used to test for differences in the mean scores of trust in different actors and concerns about different dairy-related issues. 


\section{Consumer Trust in Actors of the Dairy Supply Chain and Consumer Concerns About Dairy-Related Issues}

The mean values of consumer trust in dairy supply chain actors were all above the midpoint of the scale, which indicated that they were all trusted by the respondents, but the values differed from each other. The mean scores for government $(3.70,0.70)$ and manufacturers $(3.64,0.58)$ were significantly higher than those for retailers $(3.31,0.71)$ and farmers $(3.36,0.72)$. This showed that Chinese consumers trusted government and manufacturers more than they trusted farmers and retailers. We further compared the mean scores of 6 items of trust about 5 actors (see Table 4). We found that consumers perceived that manufacturers and government had more competence and knowledge in controlling the safety of dairy. Meanwhile, respondents believed that manufacturers and government were more concerned about and gave special attention to the safety of dairy, which, to some extent, explained why Chinese consumers trusted more in manufacturers and government.

Respondent concerns about dairy-related issues; for example, production methods, safety assurances, and health, scored 4.03 (0.73), 4.09 (0.61), and 3.31 (0.72), respectively. Comparing the mean values, we found that respondents were more concerned about issues related to production methods and safety assurance than health.

\section{Validity and Reliability of Constructs}

As mentioned above, 2 confirmatory factor analyses were conducted for milk and IMF among the 14 latent variables to examine construct validity and reliability (see Table 5). The 2 estimated measurement models showed a satisfactory fit: for milk, $\chi^{2} / \mathrm{df}=2.487$, CFI $=0.927$, RMSEA $=0.040 ;$ for IMF $, \chi^{2} / \mathrm{df}=2.486, \mathrm{CFI}$ $=0.928$, RMSEA $=0.040$.

All constructs showed satisfying validity. In the 2 models, the factor loadings of each item in all 14 latent variables were $>0.40$ and thus acceptable. All scores were statistically significant as indicated by their corresponding $P$-value $(<0.01)$, providing support for convergent validity of all constructs.

Construct reliability was assessed by 2 internal consistency indicators: CR and AVE measures. Except for the value of "pessimism" in the model for milk and the values of "trait worry" in both models, the $\mathrm{CR}$ values of the constructs in the 2 models were all $>0.70$. Both in models for milk and for IMF, the values of AVE for most of the constructs exceeded 0.50, as recommended. For the constructs "pessimism" in the model for milk, and "trust in manufacturers," "confidence

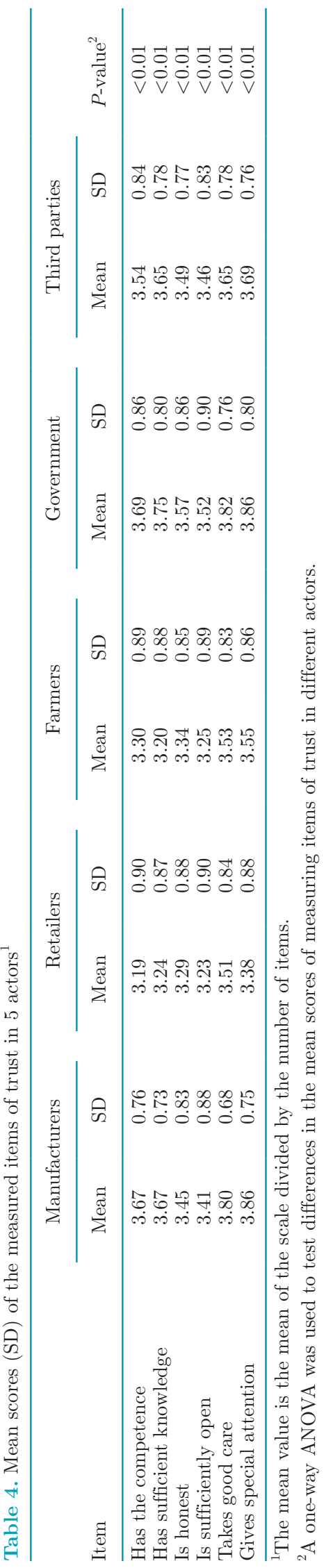


Table 5. The measurement models for milk and infant milk formula ${ }^{1,2}$

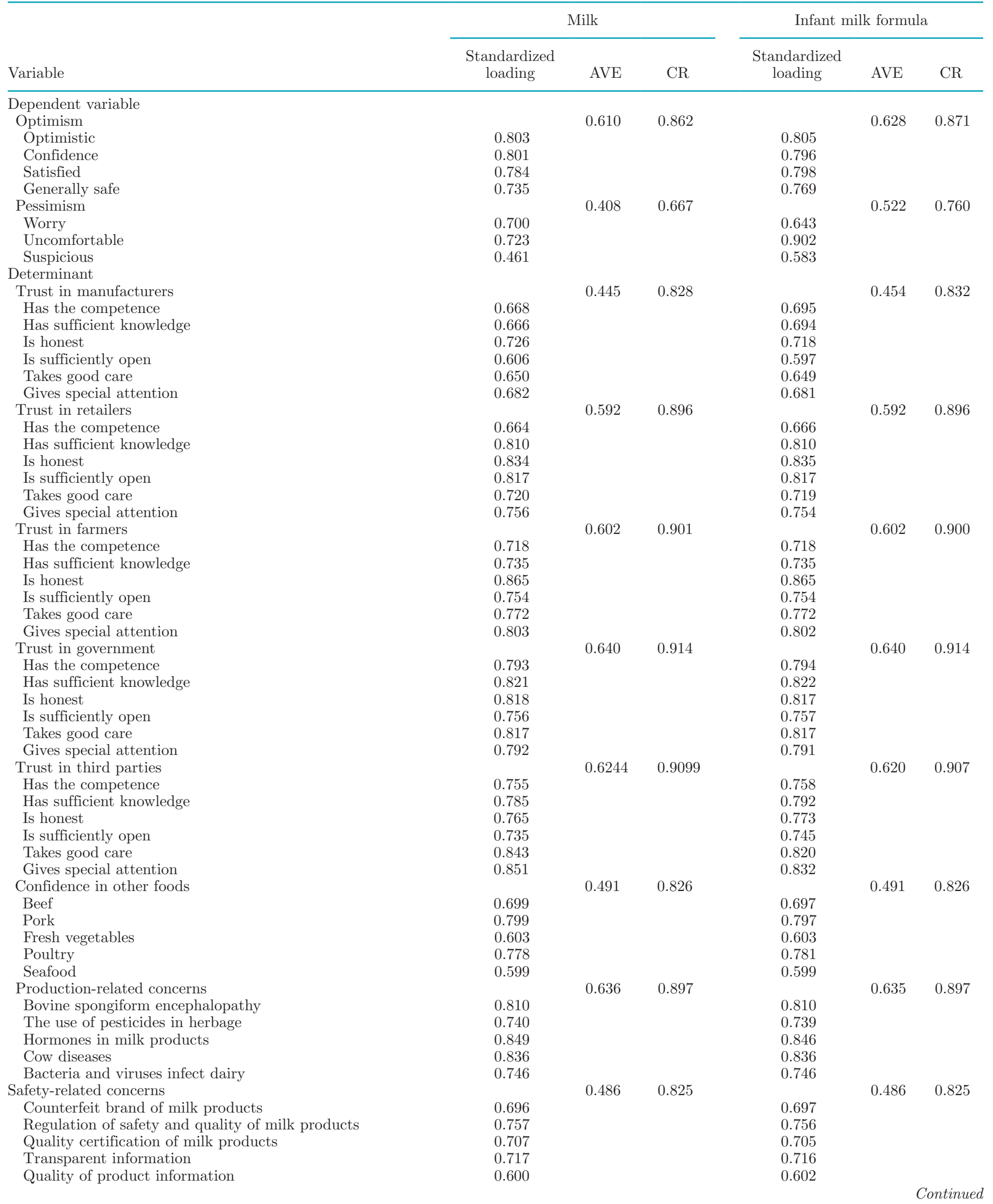


Table 5 (Continued). The measurement models for milk and infant milk formula ${ }^{1,2}$

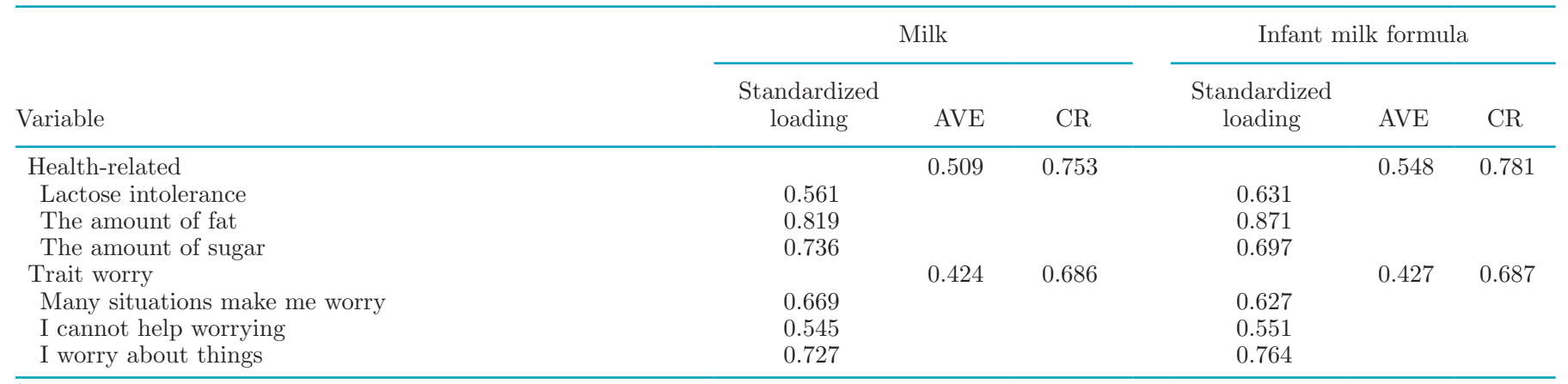

${ }^{1}$ The $P$-values of all factor loadings were $<0.001$.

${ }^{2}$ Average variance extracted (AVE) and composite reliability (CR) were used to assess the reliability of constructs.

in other foods," "safety-related concerns" and "trait worry" in both models, the values of AVE from 0.40 to 0.50 exhibited modest reliability. Overall, our models showed acceptable reliability of all constructs for our analysis, with the exception of trait worry and pessimism in milk. Although a low internal consistency of "trait worry" in both models and "pessimism" in milk suggested that items were likely measuring a construct different from the other items in the scale, the corresponding indicators of these constructs were significant. We therefore decided to retain these variables in the following analysis but we interpret the findings with careful consideration.

\section{Assessing the Structural Model}

The results from the maximum likelihood estimation suggested that the 2 structural models achieved an overall good fit $\left(\chi^{2} /\right.$ df_milk $=2.302, \chi^{2} /$ df_IMF $=2.294)$. The proposed relationships fit the data, as indicated by the summary statistics $\left(\mathrm{CFI}_{\text {milk }}=0.922\right.$, $\mathrm{RMSEA}_{\text {milk }}=0.037 ; \mathrm{CFI}_{\mathrm{IMF}}=0.921, \mathrm{RMSEA}_{\mathrm{IMF}}=$ 0.037). The standardized structural factor loadings are displayed in Table 6 .

Among the 5 main actors in the dairy supply chain, trust in manufacturers and trust in third parties had significantly positive effects on consumer confidence in the safety of milk and IMF. Trust in manufacturers was the strongest predictor of consumer confidence. It might be that consumers perceive manufacturers to be more responsible for the safety of milk and IMF than other actors. Consumer trust in third parties was found to only significantly increase optimism and reduce pessimism about the safety of IMF, so trust in third parties played a more positive role in consumer confidence in IMF.

Consumers who lack confidence in other foods were likely to be more pessimistic and less optimistic about the safety of milk and IMF. This suggests that food safety incidents that are related to other specific products, such as pork and beef, not only increase consumers' worry about the safety of these products but also make consumers more concerned about the safety of dairy.

The consumers' extent of recall of the 2008 melamine incident had a significantly negative effect on consumer confidence in milk and IMF. The better consumers remember that incident, the less optimistic and more pessimistic they are about the safety of milk and IMF. Consumers' recall of food safety incidents in general was not strongly related to consumer confidence in the safety of milk and IMF. It might be that consumers did not recall a food safety incident in the past 6 mo or that the food safety incidents recalled were not related to dairy products or were less serious than the melamine incident.

Among individual differences, trait worry was significantly related to consumer confidence in the safety of milk and IMF. Trait worry reduced optimism and increased pessimism about milk but increased pessimism only in regard to the safety of IMF. As expected, education also negatively affects consumer confidence about the safety of milk and IMF. Consumers with higher levels of education are less optimistic about milk and IMF.

Interestingly, family income and the number of children in a family were found to be only significantly related to consumer confidence in the safety of IMF. Consumers with less family income or more children are more confident in Chinese IMF. One of the reasons for these results might be that consumers with less income and more children are not able to afford imported IMF and therefore have more purchase experience with cheaper Chinese IMF. The consumption experiences of Chinese IMF are likely to improve perceptions of safety and enhance consumer confidence. We additionally analyzed the consumption behavior for consumers with different numbers of children and different levels 
of income (see Appendix Table A2, Table A3). The results showed that consumers with less income and more children indeed preferred purchasing Chinese IMF.

\section{DISCUSSION}

This study measured Chinese consumer confidence in the safety of domestically produced dairy and investigated its determinants. In particular, we applied a 2-dimensional scale measuring optimism and pessimism to measure consumer confidence in 2 specific dairy products, milk and IMF. We examined how consumer trust in the main actors of the dairy supply chain, confidence in other foods, memories of food safety incidents, concerns about dairy issues, trait worry, and consumer sociodemographics affect consumer confidence in milk and IMF. The results showed the need to formulate further food control strategies, such as quality certification of milk products, transparent information about production, and quality of information on labels of milk products, throughout the different actors of the dairy chain, and to develop a framework of consumer confidence in dairy products. Our results highlight the need to formulate targeted risk communication strategies for different dairy products.

The results showed that Chinese consumers were satisfied and optimistic about the safety of milk and IMF; at the same time, they had concerns and were suspicious about risks related to the consumption of milk and IMF. These findings corroborate those of de Jonge et al. (2007), in that optimism and pessimism are 2 related but distinct dimensions of consumer confidence that can coexist. Chinese consumers were less confident about the safety of IMF than they were about the safety of milk, which is consistent with insights into China from the Dairy Association of China/Ministry of Agriculture and Rural Affairs of China (2018). This indicates that improvement of consumer confidence in IMF requires additional attention. However, consumers with lower family income or more children had greater confidence in the safety of Chinese IMF. Consumers with lower family income or more children were the main groups who preferred to purchase Chinese IMF because of its affordable price. Given that the safety of Chinese IMF has been greatly improved since the melamine incident, they might have satisfying consumption experiences with Chinese IMF, which could lead to more familiarity and stimulate benefit perception (Fischer and Frewer, 2009), thus strengthening their confidence in Chinese IMF. In comparison, consumers with higher family income or fewer children, who have relatively higher food budgets and are more capable to purchase imported IMF, might have higher requirements and expectations for the safety of IMF. Affected by safety incidents of Chinese IMF, they might be harder to satisfy with the safety of Chinese IMF.

Table 6. Structural regression coefficients (standardized; SE in parentheses) of models for milk and infant milk formula

\begin{tabular}{|c|c|c|c|c|}
\hline Variable & \multicolumn{2}{|c|}{ Milk } & \multicolumn{2}{|c|}{ Infant milk formula } \\
\hline \multicolumn{5}{|l|}{ Trust } \\
\hline Retailers & $0.044(0.033)$ & $0.003(0.044)$ & $0.090(0.038)^{*}$ & $-0.066(0.040)$ \\
\hline Farmers & $0.044(0.037)$ & $-0.020(0.049)$ & $0.048(0.043)$ & $0.033(0.046)$ \\
\hline Government & $-0.012(0.043)$ & $0.102(0.057)$ & $-0.109(0.051)^{*}$ & $0.098(0.053)$ \\
\hline \multicolumn{5}{|c|}{ Concerns about milk-related issues } \\
\hline Health-related & $0.031(0.037)$ & $0.029(0.048)$ & $0.048(0.042)$ & $-0.060(0.045)$ \\
\hline Safety assurance & $0.117(0.074)$ & $-0.148(0.097)$ & $-0.068(0.087)$ & $0.184(0.092)^{*}$ \\
\hline Production method & $-0.092(0.042)$ & $0.133(0.055)^{*}$ & $0.058(0.048)$ & $-0.042(0.051)$ \\
\hline \multicolumn{5}{|l|}{ Safety incident } \\
\hline Recall of melamine incident & $-0.184(0.017)^{* * *}$ & $0.243(0.023)^{* * *}$ & $-0.180(0.020)^{* * *}$ & $0.170(0.021)^{* * *}$ \\
\hline Recall over past 6 mo & $0.024(0.038)$ & $0.008(0.050)$ & $-0.032(0.044)$ & $0.090(0.047)^{*}$ \\
\hline Self-health evaluation & $0.027(0.020)$ & $-0.032(0.026)$ & $0.007(0.023)$ & $-0.038(0.025)$ \\
\hline Lactose intolerant & $-0.046(0.079)$ & $-0.008(0.104)$ & $-0.058(0.092)^{*}$ & $0.019(0.097)$ \\
\hline Family income & $-0.013(0.022)$ & $0.005(0.029)$ & $-0.102(0.026)^{* * *}$ & $0.107(0.027)^{* *}$ \\
\hline Number of children in family & $-0.019(0.025)$ & $0.049(0.033)$ & $0.094(0.030)^{* *}$ & $-0.017(0.031)$ \\
\hline
\end{tabular}

\footnotetext{
${ }^{* * *} P<0.001 ;{ }^{* *} P<0.01 ;{ }^{*} P<0.05$.
} 
Consumer confidence in the safety of milk and IMF was most strongly affected by trust in actors of the dairy supply chain, followed by confidence in other foods and the extent of recall of the 2008 melamine incident. The effect of trust on consumer confidence in milk and IMF varied with the type of actor. Among the 5 identified actors, trust in manufacturers played the strongest role in enhancing optimism and reducing pessimism for the safety of milk and IMF, consistent with the findings of de Jonge et al. (2007). This suggests that building consumer trust in manufacturers may generate more consumer confidence in milk and IMF. Moreover, trust in third parties could increase optimism and reduce pessimism for IMF but not for milk. Compared with milk, IMF plays a crucial role in infant health in the short and long term, and requires stricter safety standards. Meanwhile, the Chinese are very concerned about the health of their children because of the long-term effects of the One Child policy in China. Therefore, Chinese consumers might believe that supervision from multiple parties is needed to guarantee the safety of IMF rather than milk. Consumers who trust in third parties are more confident in IMF and believe that third parties are able to guarantee food safety. This indicates that the activities of third parties should focus on building trust with consumers, which might be an effective strategy to enhance consumer confidence in IMF. Our identification of diverse effects of consumer trust in different actors supports the conclusion of de Jonge et al. (2007) that consumer confidence can be enhanced by trust but the strength of this relationship varies with the type of actor. Next, we identified the relationship between consumer confidence in dairy products and confidence in other foods. Consumers who lacked confidence in other foods were likely to be less optimistic and more pessimistic about the safety of milk and IMF. This result suggests that the dairy supply chain should also be aware of the negative influence of other food incidents. With regard to consumers' recall of incidents, our results show that safety incidents have a long-term influence on consumer confidence. Although the melamine incident happened $10 \mathrm{yr}$ ago, it still affects consumer confidence in dairy products. The finding that consumers are more pessimistic about IMF is consistent with the fact that the melamine incident was mainly related to IMF. This is also in line with de Jonge et al. (2007), who show that recall of an incident has a strong effect on pessimism.

Given the negative effect of safety incidents on consumer confidence, it is important for the dairy supply chain and regulatory institutions to take measures to enhance optimism and reduce pessimism in Chinese consumers. According to Li et al. (2018), Chinese con- sumers who lack confidence prefer IMF with farm-totable traceability. Therefore, the existing traceability system in China should be improved to enable the dairy chain to provide more auditable information to strengthen consumer confidence. There are roles for different actors along the dairy chain for building trust, especially dairy manufacturers and third parties. For instance, dairy enterprises could present more transparent information about production practices and quality control measures and provide quality information on labels of dairy products. Third parties should improve their authority by, for example, providing more professional and reliable quality certifications of dairy products. As trust in third parties has a positive effect on consumer confidence in IMF, third parties especially should be more actively involved in guarding the safety of IMF, such as publicizing more information about their activities in the management of dairy safety, to increase consumer understanding of their role in quality control. Even if safety incidents related to other food products occur, there is a serious need to pay attention to maintaining consumer confidence in dairy. The main actors in the dairy chain, especially dairy companies, distributors, and retailers, have a responsibility to inform consumers to clarify the safety of dairy products.

This study also shows the need for future research. The internal consistency of the measurement scale of trait worry is low, in line with Gong et al. (2012) and Xun (2011). Unfortunately, these studies did not explain why this occurred in the context of China. Additionally, the reasons why Chinese consumers responded differently to the items of the construct of pessimism remain unclear. It would be interesting to investigate these questions in future studies. For example, stylistic responding is a source of measurement error that biases the assessment of true scores on measurement scales (Baumgartner and Steenkamp, 2001). One direction of further research is to identify the influence of stylistic response and its potential causes to improve these measurement scales, especially when applied in the context of China. It is also desirable to develop and validate new measurement scales for Chinese consumers to better understand pessimism and trait worry. As suggested by our results, the actors along the dairy chain should provide more transparent information to compensate consumers' lack of knowledge of dairy safety. Especially the position of a traceability system related to lack of knowledge needs attention. It would be valuable to investigate the effect of a traceability system on consumers' confidence and how this traceability system enables actors along the dairy chain to provide more transparent and auditable information for consumers. In addition, the findings of this study are 
limited to consumers in relatively developed areas in China. Therefore, future research is warranted to generate similar data for consumers in less-developed areas.

In conclusion, Chinese consumers remain concerned about the safety of domestically produced dairy products, especially IMF. Consumer confidence in the safety of milk and IMF is strongly influenced by consumer trust in actors of the dairy supply chain (especially manufacturers and third parties), confidence in other foods, and the degree to which they remember the 2008 melamine incident.

\section{ACKNOWLEDGMENTS}

This study was funded by a grant from the SinoDutch Dairy Development Centre of China Agricultural University (No. SDDDC2017R02) and the Ministry of Agriculture and Rural Affairs of the Peoples Republic of China (No. 05162130111242003).

\section{REFERENCES}

Anderson, J. C., and D. W. Gerbing. 1988. Structural equation modeling in practice: A review and recommended two-step approach. Psychol. Bull. 103:411-423. https://doi.org/10.1037/0033-2909 .103.3.411.

Baumgartner, H., and J. B. E. M. Steenkamp. 2001. Response styles in marketing research: A cross-national investigation. J. Mark. Res. 38:143-156. https://doi.org/10.1509/jmkr.38.2.143.18840.

Berg, L., U. Kjaernes, E. Ganskau, V. Minina, L. Voltchkova, B. Halkier, and L. Holm. 2005. Trust in food safety in Russia, Denmark and Norway. Eur. Soc. 7:103-129. https://doi.org/10.1080/ 1461669042000327045.

Blunch, N. J. 2008. Introduction to Structural Equation Modelling Using SPSS and AMOS. Sage, London, UK.

Bollen, K. A. 1989. Structural Equations with Latent Variables. Wiley, New York, NY.

Browne, M. W., and R. Cudeck. 1993. Alternative ways of assessing model fit. Pages 136-162 in Testing Structural Equation Models. K. Bollen and J. Long, ed. Sage, Newbury Park, CA.

Carmines, E. G., and J. P. McIver. 1981. Analyzing models with unobserved variables: analysis of covariance structures. Pages 65-115 in Social Measurement: Current Issues. G. W. Bohrnstedt and E. F. Borgatta, ed. Sage, Beverly Hills, CA.

Costello, A. B., and J. W. Osborne. 2005. Best practices in exploratory factor analysis. Pract. Assess., Res. Eval. 10:1-9. http:// pareonline.net/getvn.asp? $\mathrm{v}=10 \& \mathrm{n}=7$.

Dairy Association of China/Ministry of Agriculture and Rural Affairs of China. 2018. Quality report of Chinese dairy industry. Accessed Dec. 27, 2018. https://www.sohu.com/a/249781647_470064.

de Jonge, J. 2008. A monitor for consumer confidence in the safety of food. PhD Thesis. Wageningen University, the Netherlands.

de Jonge, J., H. van Trijp, R. J. Renes, and L. Frewer. 2007. Understanding consumer confidence in the safety of food: its two-dimensional structure and determinants. Risk Anal. 27:729-740. https:/ /doi.org/10.1111/j.1539-6924.2007.00917.x.
Field, A. 2009. Discovering Statistics using SPSS. 3rd ed. Sage, London, UK.

Fischer, A. R. H., and L. J. Frewer. 2009. Consumer familiarity with foods and the perception of risks and benefits. Food Qual. Prefer. 20:576-585. https://doi.org/10.1016/j.foodqual.2009.06.008.

Fornell, C., and D. F. Larcker. 1981. Evaluating structural equation models with unobservable variables and measurement error. J. Mark. Res. 18:39-50. https://doi.org/10.2307/3151312.

Gebhardt, W. A., and J. F. Brosschot. 2002. Desirability of control: Psychometric properties and relationships with locus of control, personality, coping, and mental and somatic complaints in three Dutch samples. Eur. J. Pers. 16:423-438. https://doi.org/10.1002/ per.463.

Gong, S., L. Bai, and J. Chen. 2012. Chinese consumer confidence in food safety based on the model of structural equation. Consumer Economics 28:53-57. [in Chinese]

Harbin Bureau of Statistics. 2018. Statistical bulletin on national economic and social development of Harbin in 2017. Accessed Jan. 3, 2019. http://www.stats-hlheb.gov.cn/xw!detaPage.action?tid= 47024\&type_no=201.

Lassoued, R., J. E. Hobbs, E. T. Micheels, and D. D. Zhang. 2015. Consumer trust in chicken brands: A structural equation model. Can. J. Agric. Econ. 63:621-647. https://doi.org/10.1111/cjag .12082 .

Li, S., C. Zhu, Q. Chen, and Y. Liu. 2018. Consumer confidence, product attributes and consumer preferences for domestically produced infant formulas in urban northern China. J. Integr. Agric. https:/ /doi.org/10.1016/S2095-3119(19)62589-X.

Lu, F. 2010. The study of consumer trust on food safety after a significant food safety incident based on the investigation of Sanlu milk powder incident. MS Thesis. Huazhong Agricultural University, Wuhan, China. [in Chinese]

National Bureau of Statistics of China. 2018. China Statistics Yearbook. China Statistics Press, Beijing, China.

Nunnally, J. C. 1978. Psychometric Theory. 2nd ed. McGraw-Hill, New York, NY.

People's Daily. 2012. Ministry of Health: China's food melamine limit is consistent with international standards. Accessed May 13, 2019. http://politics.people.com.cn/n/2012/0706/c1001-18462838.html.

Qiao, G., T. Guo, and K. K. Klein. 2010. Melamine in Chinese milk products and consumer confidence. Appetite 55:190-195. https:// doi.org/10.1016/j.appet.2010.05.047.

Shijiazhuang Bureau of Statistics. 2018. Statistical bulletin on national economic and social development of Shijiazhuang in 2017. Accessed Jan. 3, 2019. http://www.sjztj.gov.cn/hscms/webpage/001/article .jsp?fchannelidenty $=\% \mathrm{E} 7 \% \mathrm{BB} \% 9 \mathrm{~F} \% \mathrm{E} 8 \% \mathrm{AE} \% \mathrm{~A} 1 \% \mathrm{E} 5 \% 85 \% \mathrm{AC}$ $\% \mathrm{E} 6 \% 8 \mathrm{~A} \% \mathrm{~A} 5 \&$ articleId=8a8da0b061c6d4de016275e6e69f2c74\&tp $=1$.

Wang, Z., Y. Mao, and F. Gale. 2008. Chinese consumer demand for food safety attributes in milk products. Food Policy 33:27-36. https://doi.org/10.1016/j.foodpol.2007.05.006.

Xi'an Bureau of Statistics. 2018. Xi'an Statistical Yearbook. China Statistics Press, Beijing, China.

Xiu, C., and K. K. Klein. 2010. Melamine in milk products in China: Examining the factors that led to deliberate use of the contaminant. Food Policy 35:463-470. https://doi.org/10.1016/j.foodpol 2010.05.001.

Xu, X., X. Wu, W. Feng, Y. Zhang, H. Wang, Y. Shi, J. Zhang, and H. Ding. 2011. The study on urban residents' confidence in the food safety confidence and the influencing factor. Mod. Prev. Med. 38:3643-3645. [in Chinese]

Xun, N. 2011. The evaluation research of consumer confidence in the safety of food based on the structural equation modelling. MS Thesis. Jilin University, China. [in Chinese] 


\section{APPENDIX}

Table A1. Items for consumer concerns about dairy-related issues ${ }^{1,2}$

To what extent are you concerned about the following issues?

Process method

Bovine spongiform encephalopathy

The use of pesticides in herbage

Hormones in milk products

Cow diseases

Bacteria and viruses infect dairy products

Health related

Lactose intolerance

The amount of fat in milk products

The amount of sugar in milk products

Safety assurance

Counterfeit brands of dairy products

Regulation of safety and quality of milk products

Quality certification of milk products

Transparent information about production

Quality of information on labels of milk products

${ }^{1}$ All items were rated as follows: $1=$ not at all concerned; $2=$ slightly concerned; $3=$ somewhat concerned; $4=$ moderately concerned; $5=$ extremely concerned.

${ }^{2}$ Eight items were removed using backward selection when factor loadings were $<0.60$ and when the items strongly loaded on 2 or more factors. The items removed were conditions in which cows are raised; price of milk products; the feed given to cows; health and nutrition; antibiotics in milk products; genetically modified milk products; reconstituted milk; and the use of additives in dairy products.

Table A2. The consumption of infant milk formula (of Chinese or foreign origin) among consumers with different numbers of children

\begin{tabular}{lccccc}
\hline & \multicolumn{5}{c}{ The consumption of infant milk formula } \\
\cline { 2 - 5 } No. of children $^{1}$ & Chinese & Foreign & Both & Never buy & Total \\
\hline 0 & 82 & 44 & 5 & 399 & 530 \\
1 & 124 & 82 & 7 & 100 & 313 \\
2 & 52 & 13 & 1 & 22 & 88 \\
3 & 1 & 0 & 1 & 0 & 2 \\
4 & 1 & 0 & 0 & 0 & 1 \\
Total & 260 & 139 & 14 & 521 & 934 \\
\hline
\end{tabular}

${ }^{1}$ Children are defined as persons under the age of $16 \mathrm{yr}$ in the household. For the 131 consumers with no children, children in their family have grown up. These respondents reported what kinds of infant milk formula were consumed when the children in their household were of age.

Table A3. The consumption of infant milk formula among consumers with different levels of family income

\begin{tabular}{lccccc}
\hline & \multicolumn{5}{c}{ Consumption of infant milk formula } \\
\cline { 2 - 6 } Monthly income $^{1}$ & Chinese & Foreign & Both & Never buy & \multirow{2}{*}{ Total } \\
\hline US\$0-US\$794 $_{\text {US } \$ 794-U S \$ 1,589}$ & 114 & 27 & 3 & 219 & 363 \\
>US\$1,589 & 101 & 45 & 4 & 180 & 330 \\
Total & 45 & 67 & 7 & 122 & 241 \\
\hline
\end{tabular}

${ }^{1} \$ 1=6.2933$ yuan (accessed on April 21, 2018). 